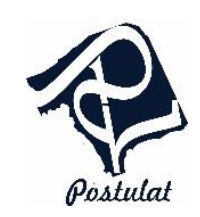

Jurnal Inovasi Pendidikan Matematika

Volume 1, Nomor 2, Desember 2020

\title{
Analisis Kesalahan Siswa dalam Menyelesaikan Soal Kemampuan Pemecahan Masalah Matematis Siswa Sekolah Menengah Atas
}

\author{
Sufri Mashuri ${ }^{1}$, Nasruddin $^{1 *}$, Sarida $^{2}$ \\ Program Studi Pendidikan Matematika Universitas Sembilanbelas November Kolaka ${ }^{1}$ Jl. Pemuda, Tahoa, \\ Kec. Kolaka, Kabupaten Kolaka, Sulawesi Tenggara 93561;sufri13@gmail.com \\ Program Studi Pendidikan Matematika Universitas Sembilanbelas November Kolaka ${ }^{*}$; Jl. Pemuda, Tahoa, \\ Kec.Kolaka, Kabupaten Kolaka, Sulawesi Tenggara 93561;nash.matematika@gmail.com \\ Program Studi Pendidikan Matematika Universitas Sembilanbelas November Kolaka ${ }^{2}$; Jl. Pemuda, Tahoa, \\ Kec.Kolaka, Kabupaten Kolaka, Sulawesi Tenggara 93561; saridarida553@ gmail.com
}

\begin{abstract}
This study aims to describe the types of student errors and the factors causing the errors made by students of class X SMA Negeri 2 Mawasangka Tengah. Solving problem solving problems based on Polya's completion steps consists of four stages, namely understanding the problem, compiling a plan, implementing the plan, and checking the answers that have been obtained. The type of error referred to in this research is the type of error based on Polya's resolution steps, namely errors in understanding the questions, errors in planning, errors in implementing the plan and errors in checking the answers that have been obtained. This research is descriptive qualitative. The instrument used was a test description consisting of 5 questions. The subjects of this study were students of class X SMA Negeri 2 Mawasangka Tengah. The results of the research conducted showed that there were four types of students of class X SMA Negerui 2 Mawasangka Tengah in understanding the questions of $31.70 \%$; errors in planning $36.58 \%$; errors in implementing the plan amounted to $35.60 \%$; and the error of checking back the answers that have been obtained is 59.51\%. In this study, the factors that cause student errors in solving mathematical problem solving are limited to the factors that cause internal errors.
\end{abstract}

Keywords: student error analysis, mathematical problem solving.

\begin{abstract}
Abstrak
Penelitian ini bertujuan untuk mendeskripsikan jenis-jenis kesalahan siswa dan faktor penyebab terjadinya kesalahan yang dilakukan siswa SMA. Penyelesaian soal pemecahan masalah berdasarkan langkah penyelesaian Polya terdiri dari empat tahap, yatu memahami soal, menyusun rencana, melaksanakan rencana, dan memeriksa kembali jawaban yang telah diperoleh. Jenis kesalahan yang dimaksud dalam penelitian ini adalah jenis kesalahan berdasarkan langkah penyelesaian Polya, yaitu kesalahan memahami soal, kesalahan menyusun rencana, kesalahan melaksanakan rencana dan kesalahan memeriksa kembali jawaban yang telah yang diperoleh. Jenis penelitian ini adalah penelitian deskriptif kualitatif dengan jumlah sampel 40 orang siswa. Instrumen yang digunakan yaitu berupa tes uraian yang terdiri dari 5 soal. Hasil penelitian yang dilakukan menunjukan bahwa terdapat empat jenis kesalahan yang dilakukan siswa saat menyelesaikan soal yang diberikan. Kesalahan tersebut adalah 1) memahami soal sebesar $31,70 \%$; 2) kesalahan menyusun rencana
\end{abstract}


Sufri Mashuri ${ }^{1}$, Nasruddin $^{1 *}$, Sarida $^{2}:$ Analisis Kesalahan Siswa dalam.....

sebesar 36,58\%; 3) kesalahan melaksanakan rencana sebesar 35,60\%; dan 4) kesalahan memeriksa kembali jawaban yang telah diperoleh sebesar 59,51\%. Pada penelitian ini faktor penyebab kesalahan siswa dalam menyelesaikan soal pemecahan masalah matematis adalah faktor internal siswa.

Kata kunci: Analisis kesalahan siswa, pemecahan masalah matematis.

INFO ARTIKEL

ISSN $: 2733-0597$
e-ISSN $: 2733-0600$
DOI $:$ http://dx.doi.org/10.30587/postulat.v1i2.2092

Submit Artikel:

2 Oktober 2020

Submit Revisi:

1 November 2020

Upload Artikel:

5 Desember 2020

\section{PENDAHULUAN}

Perkembangan ilmu pengetahuan dan teknologi informasi pada era globalisasi seperti saat ini sangatlah cepat. Perkembangan tersebut sangat mempengaruhi pendidikan di Indonesia, yang pada hakikatnya pendidikan merupakan unsur penting dalam rangka mewujudkan tujuan pendidikan dan menciptakan sumber daya manusia yang unggul, terampil, kreatif dan inovatif. Oleh karena itu, pendidikan perlu dilaksanakan secara terpadu, serasi dan teratur. Salah satu faktor pendukung pelaksanaan pendidikan yaitu pendidikan disekolah atau biasa dikenal dengan pendidikan formal (Sulistiawati, 2017; Jailani, 2018; Susanto., 2019).

Tujuan pendidikan di sekolah dioperasionalkan menjadi tujuan pembelajaran dari bidang studi yang diberikan guru di kelas (Harun, 2013). Pembelajaran adalah proses interaksi peserta didik dengan pendidik dan sumber belajar pada suatu lingkungan belajar (Nasruddin, 2017; Jailani et al., 2020). Oleh karena itu, pendidik harus mampu merancang desain pembelajaran yang dapat menarik perhatian dan partisipasi siswa agar materi yang disampaikan dapat dipahami dan dimengerti, sehingga kegiatan pembelajaran dapat terlaksana dengan baik terutama dalam pembelajaran matematika (Mardianto, 2012:54; Nasruddin et al., 2020).

Belajar matematika merupakan suatu proses pembelajaran yang dapat melatih siswa agar mampu berpikir secara logis, kritis dan kreatif untuk menyelesaikan berbagai masalah, baik masalah matematika maupun masalah lain yang menggunakan matematika untuk 
menyelesaikan masalah yang dihadapi (Yarmayani, 2016; Nasruddin, 2019). Mengingat kemampuan pemecahan masalah matematis sangatlah penting sebagai bekal kepada siswa agar setelah menyelesaikan pendidikan mereka dapat mengaplikasikannya kedalam kehidupan sehari-hari. Jadi kemampuan pemecahan masalah matematis merupakan kemampuan yang harus dimiliki oleh setiap perserta didik untuk memperoleh pembelajaran matematika yang bermakna lebih bermakna, apalagi jika proses pelaksanaannya dengan menggunakan model pembelajaran kooperatif sehingga dapat berkolaborasi dan berbagi skill (Bialik et al, 2015; Djidu \& Jailani, 2018; Nasruddin at al., 2019).

Terdapat empat indikator langkah-langkah dalam menyelesaikan soal pemecahan masalah matematis menurut Polya, yaitu: memahami masalah, merencanakan penyelesaian, melakukan perhitungan sesuai rencana, dan mengecek kembali jawaban yang telah dikerjakan (Hidayah, 2016; Harianto et al., 2019). Jadi analisis pada penelitian ini adalah melakukan analisis kesalahan yang dilakukan siswa SMA berdasarkan langkah yang dilakukan Polya dalam menyelesaiakn soal kemampuan pemecahan masalah matematis. Adapun tujuan yang ingin dicapai dalam penelitian ini adalah untuk mengetahui kesalahan siswa dalam menyelesaikan soal kemampuan pemecahan masalah, faktor-faktor yang menyebabkan siswa melakukan kesalahan serta faktor dominan yang mempengaruhi siswa dalam proses pembelajaran pada siswa kelas X SMA Negeri 2 Mawasangka Tengah dalam menyelesaikan soal kemampuan pemecahan masalah matematis.

\section{METODE PENELITIAN}

Jenis penelitian ini adalah penelitian deskriptif dengan pendekatan kualitatif. Penelitian ini dilaksanakan pada semester ganjil tahun ajaran 2020/2021. Subjek dalam penelitian ini adalah siswa kelas X SMA Negeri 2 Mawasangka Tengah dengan jumlah siswa 41 orang. Instrumen dalam penelitian ini adalah instrumen tes dan wawancara. Instrumen tes terdiri dari lima butir soal dengan tujuan untuk mengetahui jenis-jenis kesalahan siswa dalam menyelesaikan soal pemecahan masalah matematis yang mengacu pada indikator-indikator kemampuan pemecahan masalah. Rumus presentase yang digunakan untuk mengetahui tingkat kesalahan siswa adalah sebagai berikut (Rahmawati, 2018). 
$p_{i}=\frac{x_{i}}{\sum x} \times 100 \%$

[1]

Keterangan:

$p_{i} \quad=$ Presentase kesalahan siswa pada jenis ke-i

$x_{i}=$ Jumlah kesalahan siswa pada jenis ke-i

$\sum x=$ Jumlah kesalahan yang mungkin terjadi.

Dalam penelitian ini menggunakan wawancara tidak terstruktur untuk memperoleh informasi mengenai kemampuan pemecahan masalah matematis siswa pada subjek yang diteliti. Sebab pelaksanaan penelitian ini masih dalam kondisi pandemi Covid-19.

\section{HASIL PENELITIAN}

Berdasarkan hasil tes siswa dalam mengerjakan soal pemecahan masalah matematis, ditemukan beberapa jenis kesalahan yang dilakukan oleh siswa. Kesalahan-kesalahan tersebut adalah kesalahan memahami masalah, kesalahan menyusun rencana, kesalahan melaksanakan rencana dan kesalahan memeriksa kembali jawaban yang telah diperoleh. Berikut tabel jenis kesalahan siswa dalam menyelesaikan soal pemecahan masalah.

Tabel 1. Jenis-Jenis Kesalahan Siswa Dalam Menyelesaikan Soal Kemampuan Pemecahan Masalah Matematis

\begin{tabular}{llccccc}
\hline No & \multicolumn{1}{c}{ Nama } & Soal 1 & Soal 2 & Soal 3 & Soal 4 & Soal 5 \\
\hline 1 & Alfia & F & D & B,D & B,C,D & A \\
2 & Alwis & F & B,C,D & B,C,D & E & E \\
3 & Amalia t. & F & D & B,D & F & A \\
4 & Ardin & C,D & B,C,D & A,B,C,D & A,B,C,D & E \\
5 & Asrtiana & D & F & A,C,D & F & A \\
6 & Efi & F & D & B,D & E & A \\
7 & Eki & F & D & F & F & A \\
8 & Erni & F & D & C,D & F & A \\
9 & Fadli r. & B,D & B,D & B,D & E & E \\
10 & Fara fadila & F & D & B,D & E & A \\
11 & Farah & C,D & F & B,D & F & A \\
12 & Fardan & F & B,D & C,D & E & E \\
13 & Feki & F & B,D & B,D & E & E \\
14 & Fitrah r. & D & F & C,D & F & A \\
15 & Fudin & D & D & C,D & F & A \\
16 & Halidu & A & D & E & E & E \\
17 & Hudiani a. & F & B,C,D & B,D & E & E \\
18 & Iin sofyan & D & D & B,D & F & A
\end{tabular}




\begin{tabular}{llccccc}
19 & Irmaningsih & F & D & B,D & E & E \\
20 & Israwati & F & D & F & F & A \\
21 & Iyan & D & B,D & C,D & A,B,C,D & E \\
22 & Jeti p. & F & D & B,D & E & A \\
23 & Lilis & F & D & C,D & F & A \\
24 & Lukman & F & D & F & F & A \\
25 & M. farid & C,D & A,B,C,D & B,C,D & B,C,D & E \\
26 & Mikna n. & F & B,D & B,D & E & F \\
27 & Mizan & C,D & B,C,D & C,D & B,C,D & E \\
28 & Monaldin & F & B,D & B,D & E & E \\
29 & Mulida & A,B,C,D & A,B,D & E & A,B,C,D & A \\
30 & Nafil & F & D & B,D & F & A \\
31 & Nina w. & C,D & F & B,D & E & F \\
32 & Nur salfia & D & D & B,D & F & A \\
33 & Nur sazlin & F & F & C,D & F & A \\
34 & Nurul a. & C,D & A,D & A,B,C,D & E & A,B,C,D \\
35 & Nurul f. & F & F & B,D & F & A \\
36 & Olivia & D & F & C,D & F & A \\
37 & Salman & C,D & B,C,D & C,D & B,C,D & E \\
38 & Sartina & F & D & B,D & F & A \\
39 & Sefa & D & F & C,D & B,C,D & A \\
40 & Yumi r. & F & F & B,C,D & E & C,D \\
41 & Yun yasmin & C,D & F & F & F & A \\
\hline
\end{tabular}

ket. :

$\mathrm{A}=$ Kesalahan pemahaman

$\mathrm{B}=$ Kesalahan perencanaan

$\mathrm{C}=$ Kesalahan pelaksanaan rencana

$\mathrm{D}=$ Kesalahan pemeriksaan jawaban akhir

$\mathrm{E}=$ Tidak menjawab

$\mathrm{F}=$ Jawaban benar

Adapun presentase dari masing-masing jenis kesalahan yang dilakukan oleh siswa ditunjukkan pada Tabel 2 berikut.

Tabel 2. Presentase Kesalahan Siswa

\begin{tabular}{lc}
\hline \multicolumn{1}{c}{ Jenis kesalahan } & Presentase \\
\hline Kesalahan pemahaman & $31,70 \%$ \\
Kesalahan perencanaan & $36,58 \%$ \\
Kesalahan pelaksanaan & $35,60 \%$ \\
Kesalahan pemeriksaan kembali & $59,51 \%$ \\
\hline
\end{tabular}

Dari Tebel 2 di atas, akan dibahas secara singkat mengenai jenis-jenis kesalahan yang dilakukan siswa, yakni sebagai berikut. 
Sufri Mashuri ${ }^{1}$, Nasruddin $^{1 *}$, Sarida $^{2}:$ Analisis Kesalahan Siswa dalam.....

\section{Kesalahan Pemahaman}

Presentase pada kesalahan pemahaman yaitu 31,70\%, jenis pada kesalahan ini meliputi kesalahan tidak menuliskan hal yang diketahui dari soal, tidak menuliskan hal yang ditanyakan dari soal, serta tidak menuliskan hal yang diketahui maupun yang ditanyakan dari soal. penyebab siswa melakukan kesalahan ini adalah tidak mengetahui permasalahan dalam soal, lupa menuliskan hal yang diketahui dari soal, tidak mengetahui apa hal yang ditanyakan dalam soal, siswa tidak mampu mengeinterpretasi soal cetita kedalam bahasa sederhana, bahkan kebiasaan siswa yang menganggap tidak perlu dituliskan.

\section{Kesalahan Perencanaan}

Presentase pada kesalahan ini yaitu 36,58\%, jenis kesalahan ini meliputi kesalahaan siswa tidak menuliskan pemisalan variabel dari soal cerita yang diberikan, siswa tidak membuat model matematika yang sesuai dengan kalimat cerita yang ada pada soal, tidak menuliskan metode dan langkah-langkah yang akan mereka gunakan dalam menyelesaikan model matematika yang telah dibuatnya, siswa salah dalam menentukan model atau metode untuk penyelesaian soal. Pada tahap merencanakan langkah-langkah penyelesaian, siswa belum membuat secara lengkap, salah memilih model atau metode penyelesaian bahkan ada yang tidak menjawab. Adapun penyebab siswa melakukan kesalahan tersebut adalah tidak mengetahui langkah-langkah dalam menyelesaikan soal, tidak tahu metode/model yang seharusnya digunakan, tidak teliti menuliskan metode/model, tidak paham materi SPLTV.

\section{Kesalahan Pelaksanaan}

Presentase kesalahan pelaksanaan adalah 35,60\%. Jenis kesalahan siswa yaitu siswa tidak menyelesaikan model matematika yang telah dibuatnya sesuai dengan langkah-langkah penyelesaian yang telah disusunnya, salah melakukan perhitungan serta melakukan perhitungan yang tidak tuntas. Adapun penyebab dari kesalahan ini adalah siswa tidak teliti dalam melakaukan perhitungan, asal-asalan dalam menuliskan jawaban, menganggap tidak semua langkah dituliskan dalam lembar jawaban, akibat dari kesalahan sebelumnya serta kehabisan waktu.

\section{Kesalahan Pemeriksaan Kembali}


Kesalahan pemeriksaan kembali adalah tidak menuliskan kesimpulan pada akhir penyelesaian, ketidaksesuaian hasil yang diperoleh dengan kesimpulan, tanpa melalui langkah-langkah yang seharusnya diselesaikan terlebih dahulu (sistematis). Kesalahan pada tahap ini dipengaruhi oleh kesalahan perencanaan dan pelaksanaan, karena jika siswa membuat langkah penyelesaian yang salah maka hasil akhir juga akan salah, tidak teliti menyimpulkan hasil akhir serta siswa lupa menuliskan kesimpulan. Kesalahan pada tahap ini merupakan kesalahan yang paling banyak dilakukan oleh siswa dibandingkan dengan kesalahan pemahaman, perencanaan dan pelaksanaan, yaitu dengan presentase sebesar $59,51 \%$.

Selain faktor-faktor yang telah disebutkan diatas, faktor kondisi pandemi Covid-19 juga sangat mempengaruhi pembelajaran matematika terkhusus pembelajaran matematika, hal ini menjadi salah satu penyebab siswa melakukan kesalahan dalam menyelesaiakn soal. Karena pembelajaran di Sekolah dibatasi yaitu 1 jam (60 menit) tiap satu mata pelajaran, sehingga menyebabkan siswa malas untuk belajar kembali dirumah dan mempelajari kembali materi yang telah diberikan.

\section{Faktor dominan penyebab kesalahan siswa}

Berdasarkan beberapa faktor penyebab siswa melakukan kesalahan yang diperoleh dari subjek wawancara maupun faktor kondisi pada saat ini, jika ditinjau dari faktor dalam diri siswa (faktor internal) maka faktor yang paling dominan adalah kurangnya motivasi belajar siswa terhadap pembelajaran matematika tekhsusus pada materi SPLTV, sehingga ketika diberikan tes banyak siswa yang asal menjawab karena tidak mengulang atau mempelajari kembali materi yang diberikan gur di Sekolah. Siswa hanya menghapkan dan pembelajaran yang diberikan di Sekolah.

\section{KESIMPULAN, DISKUSI DAN REKOMENDASI}

\section{Kesimpulan}

1. Jenis-jenis kesalahan yang dilakukan siswa dalam menyelesaiakn soal kemampuan pemecahan masalah yaitu, kesalahan pemahaman $31,70 \%$, kesalahan perencanaan 
Sufri Mashuri ${ }^{1}$, Nasruddin $^{1 *}$, Sarida $^{2}:$ Analisis Kesalahan Siswa dalam.....

$36,58 \%$, kesalahan pelaksanaan 35,60\% dan kesalahan pemeriksaan kembali 59,51\%, sehingga dari kesalahan-kesalahan itulah berdampak pada hasil belajar siswa.

2. Faktor-faktor penyebab terjadinya kesalahan yang dilakukan siswa yaitu, tidak mampu mengidentifikasi fakta dalam soal cerita, tidak mengetahui permasalahan dari soal, kurangnya ketelitian dalam mengerjakan soal, tidak terbiasa menuliskan langkahlangkah secara sistematis.

3. Faktor dominan yang mempengaruhi siswa melakukan kesalahan adalah kurangnya motivasi belajar siswa terhadap pembelajaran matematika terkhusus materi pembelajaran SPLTV, dapat dilihat dari jawaban-jawaban siswa yang asal-asalan dalam menjawab soal.

\section{Diskusi dan Rekomendasi}

1. Bagi guru bidang studi, dalam pelaksanaan pembelajaran diharapkan untuk membuat pengembangan model soal dan variabel, sehingga siswa memiliki tambahan informasi agar siswa tidak hanya terfokus pada model soal yang sama.

2. Bagi siswa, dalam melakukan kesalahan diharapkan lebih memperbanyak latihan soalsoal pemecahan masalah agar terbiasa menjawab soal cerita dengan benar dan sistematis.

3. Bagi calon guru, hasil penelitian ini dapat digunakan sebagai tambahan informasi dalam mempersiapkan diri untuk menentukan langkah yang tepat dalam mengatasi kesalahan siswa dalam menyelesaikan soal cerita SPLTV maupun materi-materi yang lain.

\section{UCAPAN TERIMA KASIH}

Peneliti mengucapkan banyak terima kasih kepada seluruh Dosen Lingkup FKIP Universitas Sembilanbelas November Kolaka, kepada pihak SMA Negeri 2 Mawasangka dan seluh pihak-pihak yang terkait dalam proses pelaksanaan penelitian ini hingga samapi pada tahap penyajian data dan penarikan kesimpulan.

\section{DAFTAR PUSTAKA}

Djidu, H., \& Retnawati, H. (2018). Cultural values-integrated mathematical learning model to develop HOTS and character values. In E. Retnowati, A. Ghufron, Marzuki, Kasiyan, A. C. Pierawan, \& Ashadi (Eds.), Character Education for 21 st Century Global Citizens (pp. 363-370). Routledge. https://doi.org/10.1201/9781315104188-46. 
Jailani, J., Heri Retnawati, H. R., Wulandari, N. F., \& Djidu, H. (2020). Mathematical literacy proficiency development based on content, context, and process. Problems of Education in the 21 st Century, 78(1), 80-101. https://doi.org/10.33225/pec/20.78.80.

Harianto, E., Nursalam, L. O., Ikhsan, F. A., Zakaria, Z., Damhuri, D., \& Sejati, A. E. (2019). The compatibility of outdoor study application of environmental subject using psychological theories of intelligence and meaningful learning in senior high school. Geosfera Indonesia, 4(2), 201-216. https://doi.org/10.19184/geosi.v4i2.9903.

Harun, C. Z. (2013). Manajemen pendidikan karakter. Jurnal Pendidikan Karakter, 3(3), 302-308. https://doi.org/10.21831/jpk.v0i3.2752.

Hidayah, S. 2016. Analisis Kesalahan Siswa Dalam Menyelesaikan Soal Cerita Tentang Perbandingan. Prosiding Seminar Nasional Pendidikan Matematika Universitas Kanjuruhan Malang, 1, hal. 182-190.

Mardianto. M. 2012. Psikologi Pendidikan. Medan: perdana Publishing, hal.54.

Nasruddin, N., \& Jahring, J. (2019). Efektivitas penerapan model pembelajaran reciprocal teaching dalam meningkatkan kemampuan komunikasi matematis siswa. Saintifik: Jurnal Matematika, Sains, Dan Pembelajarannya, 5(1), 27-35. https://doi.org/10.31605/saintifik.v5i1.195.

Nasruddin, N., Mashuri, S., \& Jahring, J. (2019). Implementation of team assited individualization instructional strategies supported by Geogebra software to improve mathematical problem solving ability. Jurnal Pendidikan Progresif, 9(1), 16-21. http://jurnal.fkip.unila.ac.id/index.php/jpp/article/view/17910.

Nasruddin, N., Mashuri, S., \& Nafiah, U. (2020). Peningkatan hasil belajar matematika pada materi segitiga melalui pendekatan penemuan terbimbing Siswa SMP. Jurnal Penelitian Dan Pengkajian Ilmu Pendidikan: E-Saintika, 4(2), 80. https://doi.org/10.36312/esaintika.v4i2.169.

Rahmawati, D., \& Permata, L,D., 2018. Analisis kesalahan siswa dalam menyelesaikan soal cerita program linear dengan prosedur Newman. Jurnal Elektronik Pembelajaran Matematika, 5(2), hal. 173-185.

Susanto, A. (2019). Kemampuan pemahaman konsep matematis, model reciprocal teaching dan model AIR auditory intellectualy repetition. Matematika Dan Pendidikan Matematika, 3(2), 219-230. https://doi.org/10.15548/mej.v3i2.677.

Sulistiawati, D. 2017. Pengaruh model pembelajaran generative terhadap kemampuan pemecahan masalah matematika pada siswa kelas VII H dan G SMP Negeri 1 Cikarang Barat. JKPM (jurnal kajian pendidikan matematika) 2(2), hal. 219-226. Journal.Ippmunindra.ac.id.

Yarmayani, A. 2016. Analisis Kemampuan Pemecahan Masalah Matematis Siswa Kelas XI Mipa Sma Negeri 1 Kota Jambi. Jurnal Ilmiah DIKDAYA, 6(2), hal. 12-19. 